\title{
Solution-Processed Nanowire Coating for Light Management in Organic Solar Cells
}

\author{
K. Tsuboi, T. Fukawa, Y. Konosu, H. Matsumoto, and A. Tanioka \\ Department of Organic and Polymeric Materials, Tokyo Institute of Technology, Tokyo 152-8552, Japan \\ Correspondence should be addressed to H. Matsumoto, matsumoto.h.ac@m.titech.ac.jp \\ Received 10 May 2012; Accepted 5 July 2012 \\ Academic Editor: Charles M. Lukehart
}

Copyright () $2012 \mathrm{~K}$. Tsuboi et al. This is an open access article distributed under the Creative Commons Attribution License, which permits unrestricted use, distribution, and reproduction in any medium, provided the original work is properly cited.

We report a novel light management approach based on solution-processed nanowire (NW) coating for enhancing organic solar cell efficiency. A titanium dioxide $\left(\mathrm{TiO}_{2}\right) \mathrm{NW}$ dispersion was produced by electrospinning. The coatings with various coverage fractions were fabricated by a simple solution casting of a $\mathrm{TiO}_{2} \mathrm{NW}$ dispersion. Reduced reflectivity was observed for the NWcoated glass slide. The bulk-heterojunction organic solar cells with the NW coating showed improved power conversion efficiencies (PCEs) due to their antireflection and light trapping effects in the active layer. In addition, the PCE of the cell with the NW coating was improved compared with that without the NW coating for incident angles above $70^{\circ}$ (increased by a maximum of $51.6 \%$ at an incident angle of $85^{\circ}$ ). These results indicate that solution-processed NW coating is a promising light management approach easily scalable and applicable to a wide range of devices, including solar cells.

\section{Introduction}

Organic solar cells, which can be fabricated by simple processing techniques, are being intensely studied because of their potential to enable the mass production of flexible and low-cost devices $[1,2]$. Most of the attention has been focused on solution-processed polymer bulk-heterojunction $(\mathrm{BHJ})$ solar cells $[3,4]$. A combination of polymer design, morphology control, structural insight, and device engineering has led to power conversion efficiencies (PCEs) reaching the $6-8 \%$ range for conjugated polymer/fullerene blends $[5,6]$. However, the $\mathrm{BHJ}$ morphology, a bicontinuous, nanoscaled, phase-separated donor and acceptor components of organic solar cells, has an intrinsic conflict between the optical and the electronic length scales: the BHJ layer of a few hundred nm can achieve complete light absorption, but the exciton-diffusion length is only around $20 \mathrm{~nm}[7,8]$. To resolve this conflict, versatile and scalable light management techniques are strongly required for reduction of the $\mathrm{BHJ}$ film thickness with low-loss optical absorption $[9,10]$. Here we report a novel light management approach based on a solution-processed nanowire (NW) coating for enhancing organic solar cell efficiency.

For light management, in particular for antireflection coatings or light trapping in the $\mathrm{BHJ}$ layer, nanostructures play a crucial role [7-9]. However, versatile and scalable fabrication methods of nanostructures are limited. A number of approaches have been actively explored to synthesize onedimensional (1-D) nanomaterials [11]. Electrospinning has also been explored as a fast and efficient top-down process for fabricating continuous (1-D) nanomaterials composed of polymers, ceramics, carbon, and metals [12-14]. Electrospun nanofibers (NFs) are very promising as optical materials because of their strong light-scattering properties. Our previous studies showed optical applications of the electrospun NFs, such as the coloring of NF-based coatings due to the thin-film interference [15] and light-scattering assisted surface plasmon resonance at an electrospun NFcoated gold surface [16]. Herein, we used titanium dioxide $\left(\mathrm{TiO}_{2}\right)$ as the material of the nanostructures because of its high-refractive index, good transparency, good processability (applicable to solution processes through a sol-gel reaction), and low cost [10]. In addition, we used $\mathrm{TiO}_{2}$ NWs instead of continuous $\mathrm{TiO}_{2}$ NFs, because the NW enables more precise control of the coverage fraction of the nanostructure coating than NF [17]. Several researchers have reported the introduction of $\mathrm{TiO}_{2}$ NWs or NFs as a 1-D semiconductor for the active layer of organic solar cells $[17,18]$. However, solution-processed top surface coatings of solar cells using high-refractive-index NWs for light management have not 
been reported [19]. We report a novel light management approach based on solution-processed NW coating without morphological control of the active layer, which are simple, versatile, and easy scalable.

In the present study, we prepared a $\mathrm{TiO}_{2} \mathrm{NW}$ dispersion by electrospinning of a sol-gel precursor solution, titanium tetraisopropoxide/ethanol solutions containing acetic acid (catalyst) and poly(vinylpyrrolidone) (electrospinnable carrier polymer), and successive calcination and ultrasonication; the NW coating was then fabricated by a solution casting of the NW dispersion. The purposes of the present study are (i) to prepare NW coatings with various coverage fractions by a simple solution casting, and (ii) to investigate the effect of the NW coating on the performance of $\mathrm{BHJ}$ organic solar cells.

\section{Experimental}

2.1. Materials. Materials for $\mathrm{TiO}_{2} \mathrm{NWs}$, titanium tetraisopropoxide ( $\mathrm{TiP}, 97 \%$ purity, Kanto Chemical), poly (vinylpyrrolidone) (PVP, Mw = 1,300,000, Sigma-Aldrich), acetic acid (HOAc, 99.9\% purity, Wako), and dehydrated ethanol (EtOH, 99.9\% purity, Kanto Chemical) were used as received. Materials for BHJ organic solar cells, poly(3-hexylthiophene) (P3HT, Mw = 54,00075,000 , electronic grade $99.995 \%$ purity, Sigma-Aldrich), [6,6]-phenyl-C61-butyric acid methyl ester (PCBM, electronic grade $99.9 \%$ purity, Sigma-Aldrich), and poly(3,4ethylenedioxythiophene): poly(styrene sulfonate) (PEDOT: PSS, Clevious P VP. AI4083, H. C. Starck) were also used as received.

2.2. Preparation and Coating of $\mathrm{TiO}_{2}$ Nanowires. PVP was dissolved in $\mathrm{EtOH}$ to give a 5\% solution and stirred for 3 to 4 hours. The PVP, TiP, HOAc, and EtOH were mixed at the ratio of $\mathrm{TiP} / \mathrm{PVP} / \mathrm{EtOH} / \mathrm{HOAc}=26 / 2.2 / 41.8 / 30$ (in weight) and stirred for a half an hour to give a sol-gel precursor solution. The solution was prepared in a glove bag filled with nitrogen gas in order to prevent rapid sol-gel reaction before spinning. The electrospinning device was the same as that used in a previous study [20]. An aluminum plate $\left(4 \times 4 \mathrm{~cm}^{2}\right.$ area) was used as the counter electrode. Electrospinning was conducted at room temperature and relative humidity (RH) lower than $30 \%$. The applied voltage was $6 \mathrm{kV}$. The distance between the nozzle and collector was fixed at $80 \mathrm{~mm}$. The flow rate of precursor solution was $5 \mu \mathrm{L} / \mathrm{min}$. The spun fibers were collected on the counter electrode to form a free-standing fabric of about $10-\mu \mathrm{m}$ thickness. The asspun fabrics were kept under atmospheric conditions at room temperature for a couple of hours (for completion of hydrolysis of TiP in the fabrics) and then dried in vacuum for 3 to 4 hours. The dried fabrics were calcined at $500^{\circ} \mathrm{C}$ in a furnace (KDF-S70, Denken) for 1 hour to remove PVP and crystallize $\mathrm{TiO}_{2}$ NFs. X-ray diffraction (XRD) pattern of the prepared fibers shows that all peaks can be indexed to highly crystalline anatase phase $\mathrm{TiO}_{2}$ (Figure S1 available online on doi:10.1155/2012/387586). Figure 1 shows a schematic of the preparation method of the $\mathrm{TiO}_{2} \mathrm{NW}$ coating. The calcined

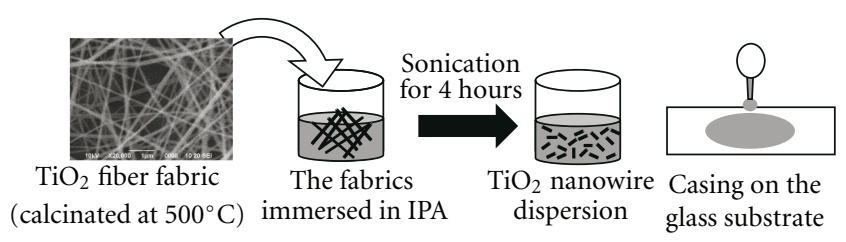

Figure 1: Schematic of preparation method of $\mathrm{TiO}_{2} \mathrm{NW}$ coating.

$\mathrm{TiO}_{2}$ NF fabrics of several hundred $\mu \mathrm{g}$ were immersed in IPA at $0.02 \mathrm{wt} \%(\mathrm{w} / \mathrm{w})$ with $1 \mathrm{wt} \%$ acetylacetone as the dispersion agent and then ultrasonicated for 4 hours to break the NFs into NWs. The obtained NW dispersion was cast on a thin glass slide $(0.12 \mu \mathrm{m}$-thick $)$ treated with UV-ozone. The casting was repeated until the coverage fraction of NWs achieved the required value.

2.3. Fabrication of BHJ Organic Solar Cells. BHJ organic solar cells, which were composed of an indium tin oxide (ITO)coated glass substrate/PEDOT:PSS/P3HT:PCBM/LiF/Al electrode, were fabricated as follows. The ITO-coated glass substrate was thoroughly cleaned by ultrasonication in detergent, ultrapure water, and IPA, followed by cleaning with a wiping cloth containing a detergent. After complete drying, the ITO-coated glass was treated with UV-ozone. A PEDOT:PSS aqueous solution was spin-coated on the ITO-coated layer to form a film of $30-\mathrm{nm}$ thickness. The coated substrate was then dried for $30 \mathrm{~min}$ at $200^{\circ} \mathrm{C}$ in air. $2.5 \mathrm{wt} \%$ P3HT : PC60BM ( $3: 2) /$ chlorobenzene solution was spin-coated on top of the PEDOT/PSS at 3,000 rpm for $45 \mathrm{sec}$. The cell was then annealed at $130^{\circ} \mathrm{C}$ for $10 \mathrm{~min}$ in air. $\mathrm{LiF}(0.7 \mathrm{~nm}$ in thickness) and $\mathrm{Al}$ (100 $\mathrm{nm}$ in thickness) were treated by deposition with thermal evaporation under vacuum at about $1 \times 10^{-6}$ Torr.

2.4. Characterization. The surface morphologies of the prepared nanostructures were observed using a scanning electron microscope (SEM, JCM-5700, JEOL) operated at $10 \mathrm{kV}$. All samples were coated with platinum. The XRD patterns of the samples were recorded on a scanning X-ray microdiffractometer (D8 Discover $\mu \mathrm{HR}$, Bruker AXS). The UV-visible reflection spectra of the prepared coating were measured using an integrating sphere, a monochromator (USB4000, Ocean Optics), and a white light from a halogen lamp (LS-1LL, Ocean Optics). A beam of the white light was incident on the sample surface placed at the entrance of the integrating sphere. The diameter of the incident beam was $3 \mathrm{~mm}$ on the sample surface and the angle of incidence, $\theta$, was $8^{\circ}$. Reflected light from the sample surface was collected by the integrating sphere and sent to a monochromator by the optical fiber from the integrating sphere. As a reference for the measurement, a thin glass slide without the coating was used.

The current density-voltage $(J-V)$ characteristics of the cells were measured using a Keithley 2400 source measure unit. Solar cell performance employed an air mass 1.5 global (AM 1.5G) solar simulator (OTENTO-SUN III, BunkohKeiki) with an irradiation intensity of $100 \mathrm{mWcm}^{-2}$. 


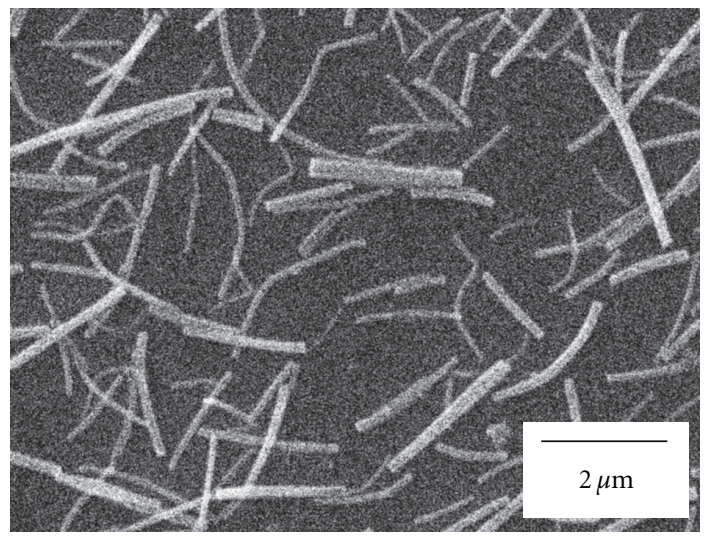

(a)

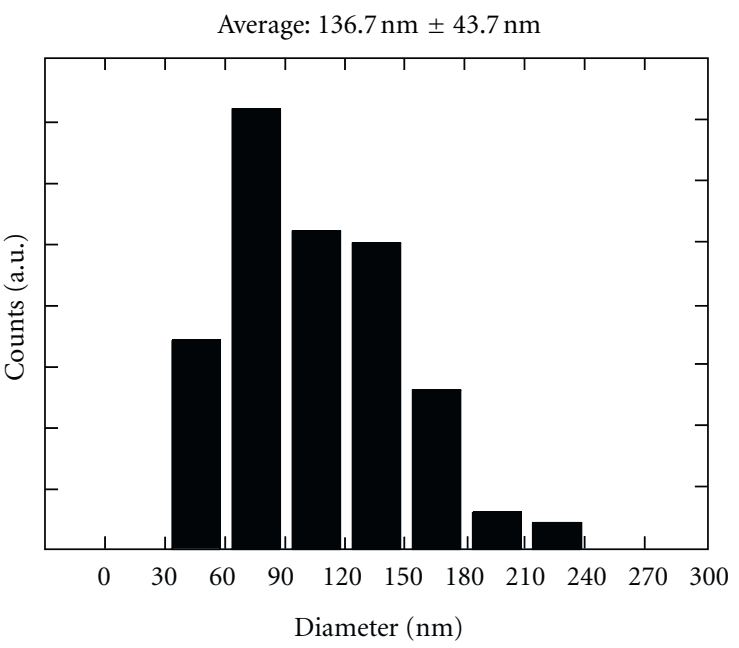

(b)

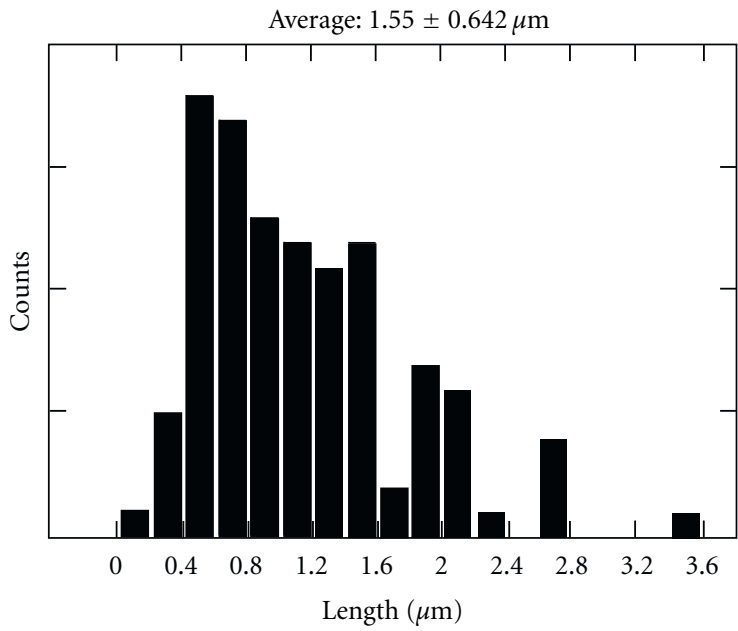

(c)

FIGURE 2: (a) SEM images of the $\mathrm{TiO}_{2}$ NW coating prepared on a silicon surface, histograms of size distribution for (b) the diameter and (c) the length of the NWs.

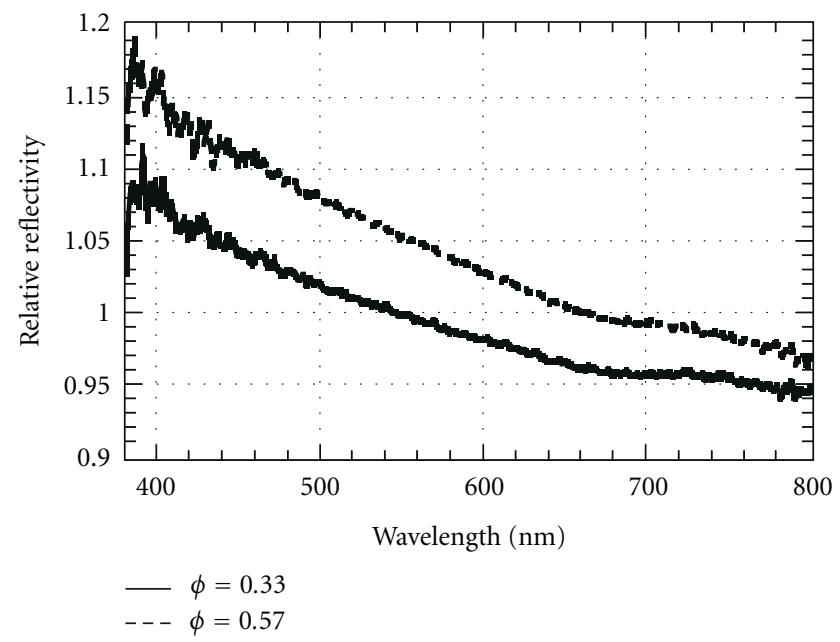

Figure 3: Typical relative reflection spectra of $\mathrm{TiO}_{2}$ NW-coated glass slide with surface coverage fraction of $\phi=0.33$ (solid line) and $\phi=0.57$ (broken line). The refractivity of 1.0 indicates the reflection of the glass slide without the NW coating.
The $\mathrm{TiO}_{2}$-NW-coated glass slide was attached onto the surface of the aperture area of the solar cell using an optical matching liquid $\left(n_{D}=1.5150\right)$. To characterize the incident angle dependency of the $J-V$ characteristics, the cell with the coated glass slide was tilted under illumination of AM 1.5G using a rotational stage. During the tilting of the cell, a He-Ne laser was irradiated on the cell surface to insure that the cell position remained at the rotation center. External quantum efficiency (EQE) spectra were measured with a MTE-1500 (Bunkoh-Keiki) including a Xe source, a monochromater, an optical chopper and a lock-in amplifier, and a silicon photodiode for monochromatic power-density calibration.

\section{Results and Discussion}

3.1. Preparation of $\mathrm{TiO}_{2} \mathrm{NW}$ Coatings. Figure 2(a) shows a SEM image of the $\mathrm{TiO}_{2}$ NW coating on a silicon surface. The average diameter $(D)$ and average length $(L)$ of the $\mathrm{TiO}_{2}$ NWs was $D=0.137 \pm 0.0437 \mu \mathrm{m}$ and $L=1.55 \pm 0.642 \mu \mathrm{m}$, respectively, (Figures 2 (b) and $2(\mathrm{c})$ ). The surface coverage fraction of the $\mathrm{TiO}_{2}$ NWs on the glass slide, $\phi$, was evaluated 


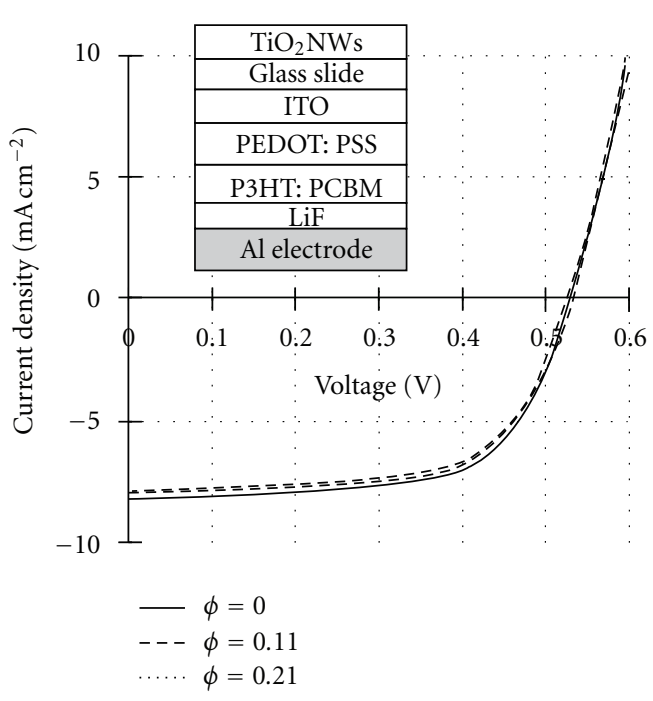

(a)

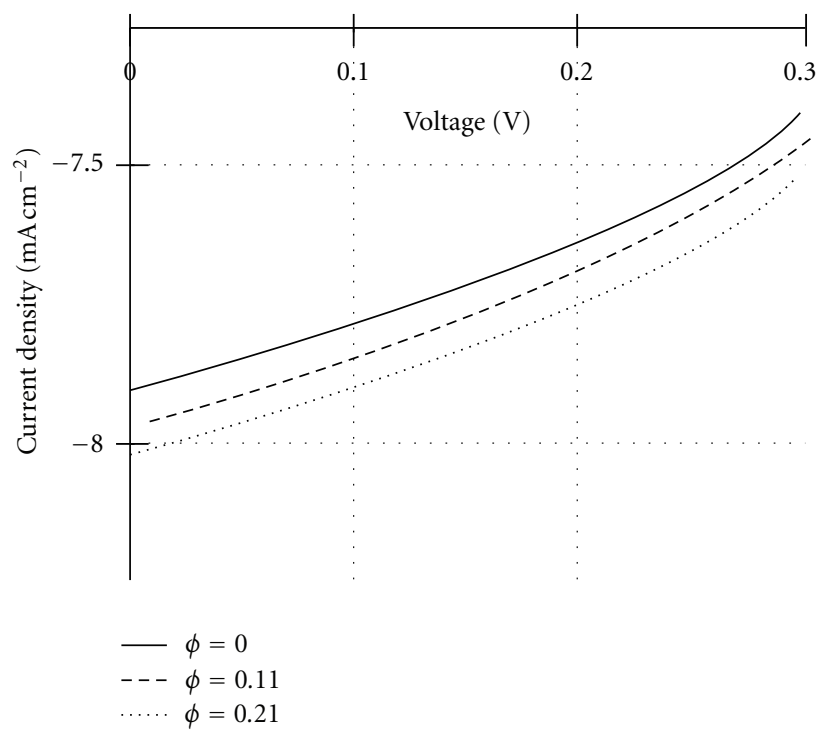

(b)

FIGURE 4: $J$ - $V$ curve obtained from $\mathrm{BHJ}$ organic solar cells with and without $\mathrm{TiO}_{2} \mathrm{NW}$ coating. (a) entire plot and (b) magnified area around $J_{\text {sc. }}$.

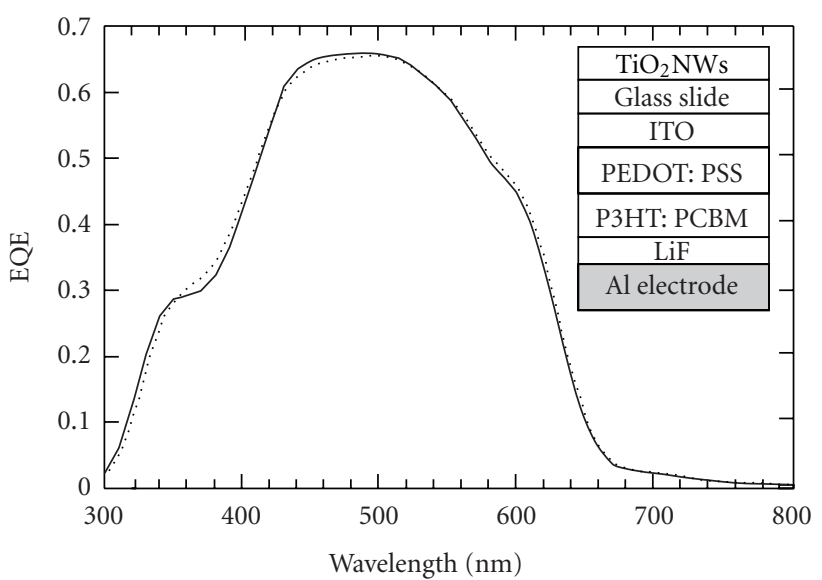

(a)

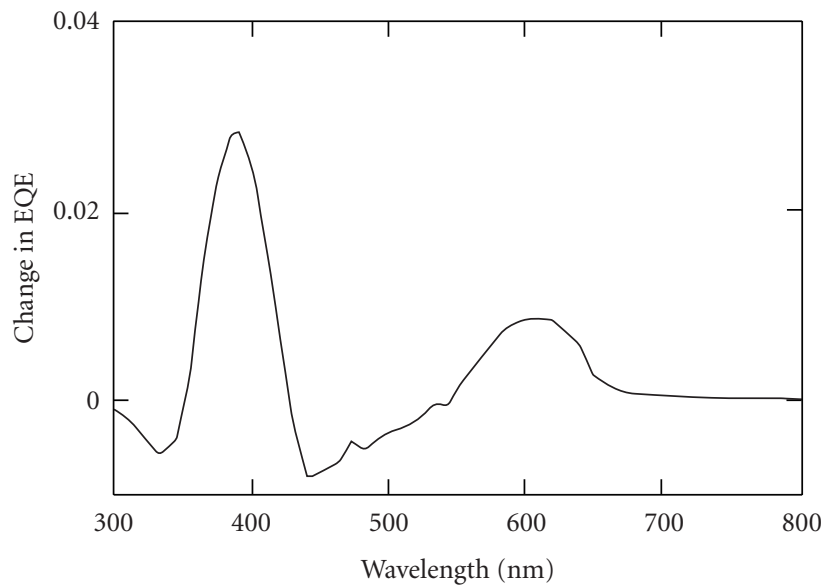

(b)

Figure 5: (a) External quantum efficiencies (EQE) of $\mathrm{BHJ}$ organic solar cells with (broken line) and without (solid line) the $\mathrm{TiO} \mathrm{N}_{2} \mathrm{NW}$ coating. (b) A change in EQEs between with and without the NW coatings.

by image analysis of the optical micrograph (Figure S2a-c). It was found that $\phi$ increased linearly with an increase in the number of castings (Figure S2d). However, with an increase in the number of castings, the number of the overlapping or agglomerates of NWs was also increased in the coatings (Figure S1a-c).

Figure 3 displays typical reflection spectra of the glass slide with NW coatings of $\phi=0.33$ and 0.57 compared with that of the glass slide without the NW coatings. The coating of $\phi=0.33$ showed an antireflective (AR) effect: lower reflectivity $(<1)$ at a wavelength of $\lambda>560 \mathrm{~nm}$. This indicates that the effective refractive index of the coating, $n_{c}$, is an intermediate value between that at atmosphere $(n=1)$ and that of the glass slide $(n=1.513)$ under an effective medium approximation [10], and the coating functions as a single layer AR coating in this wavelength region. The higher reflectivity $(>1.0)$ at the wavelength of $\lambda<560 \mathrm{~nm}$ is ascribed to the fact that the optical thickness, $n_{c} d$, of the coating is larger than a quarter of the wavelength $(\sim 137.5 \mathrm{~nm})$ : the sizes of the NWs $(D=137 \mathrm{~nm})$ deviate from the general criteria for AR coatings, $4 n_{c} d=\lambda_{0}$ in this wavelength region [10]. On the other hand, the coating of $\phi=0.57$ showed a higher reflectivity over the entire visible wavelength region. This indicates that the AR effect of the coatings would be reduced by formation of many of the overlapped NWs as observed in Figure S2c. We selected the AR coatings of $\phi<0.4$ for application to $\mathrm{BHJ}$ organic solar cells.

3.2. Performance of BHJ Organic Solar Cells with $\mathrm{TiO}_{2} \mathrm{NW}$ Coating. As shown in Figure 4, the coating slightly improved 


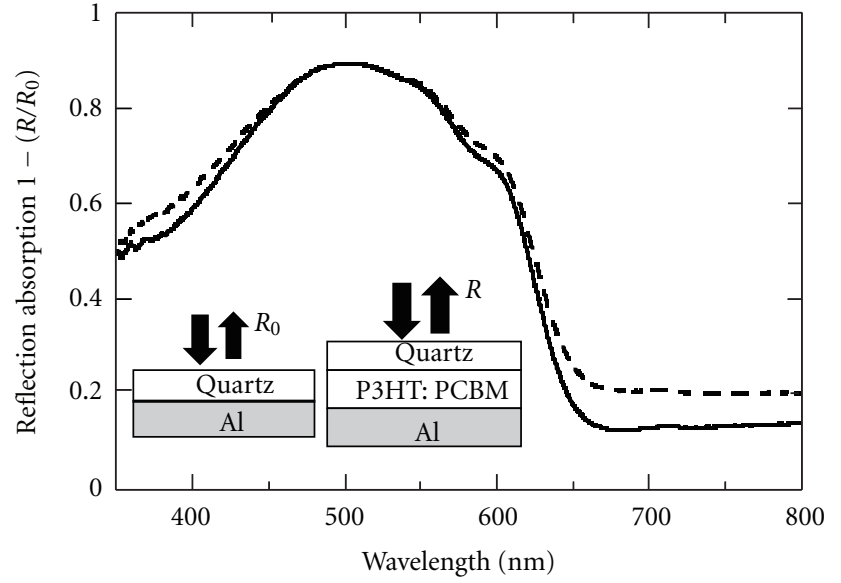

(a)

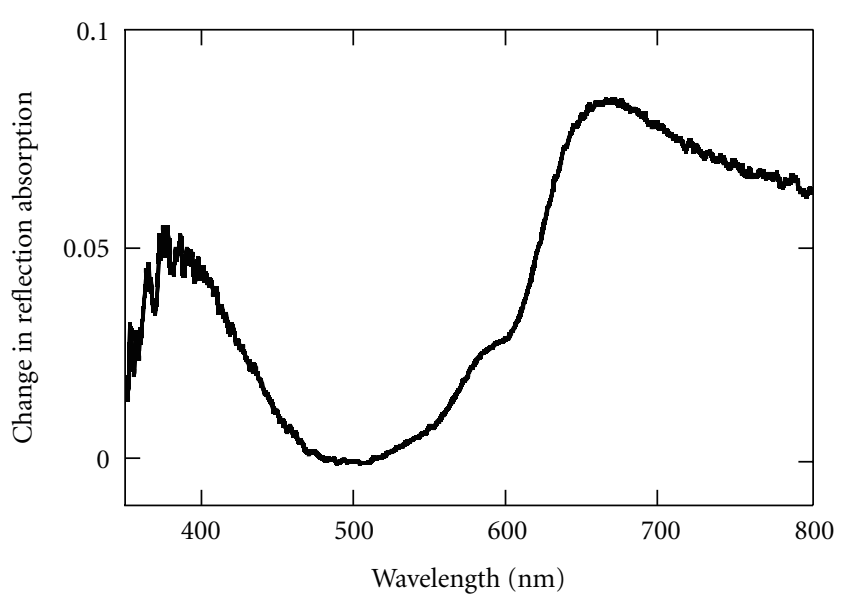

(b)

FIgure 6: (a) Reflection absorption spectra for the $\mathrm{Al}$ electrode/P3HT: $\mathrm{PCBM}$ spin-coated film on quartz with and without the TiO $\mathrm{NW}_{2}$ coating. (b) A change in reflection absorptions between with and without the NW coatings.

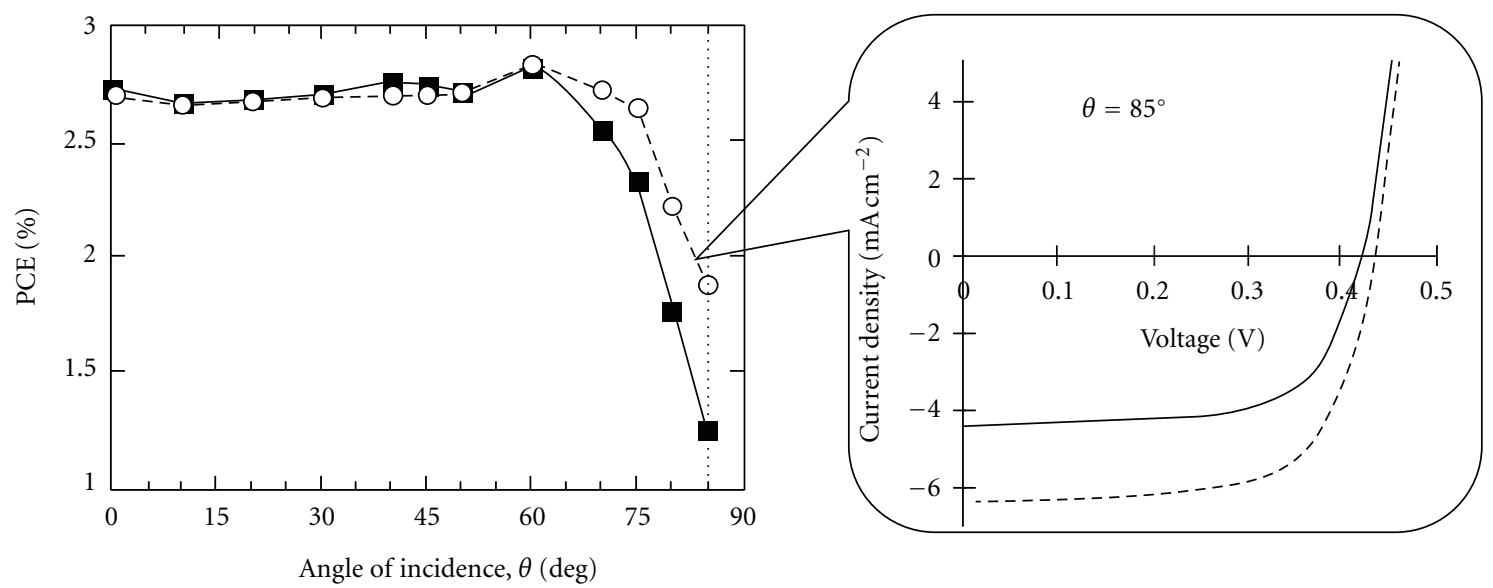

Figure 7: Comparisons of incident angle dependencies of PCE between BHJ organic solar cells of P3HT: PCBM with ( $\bigcirc)$ and without ( $\mathrm{TiO}_{2} \mathrm{NWs}$, and their typical $J-V$ curves $\left(\right.$ at $\theta=85^{\circ}$ ).

the short circuit current $\left(J_{\mathrm{sc}}\right)$ from 7.90 to $8.00 \mathrm{~mA} / \mathrm{cm}^{2}$, and the PCE obtained from the relation of

$$
\operatorname{PCE}(\%)=\frac{V_{\mathrm{oc}}(\mathrm{V}) \times J_{\mathrm{sc}}\left(\mathrm{mAcm}^{-2}\right) \times \mathrm{FF}}{100\left(\mathrm{mWcm}^{-2}\right)} \times 100
$$

was increased from 2.67 to $2.70 \%$. The performances of $\mathrm{BHJ}$ organic solar cells with and without the $\mathrm{TiO}_{2} \mathrm{NW}$ coating are summarized in Table 1. For all the coatings, the current density $J_{s c}$, which is proportional to the power density of light [21], was improved. This clearly shows the enhancement effect of light intensity in the active layer due to the $\mathrm{TiO}_{2} \mathrm{NW}$ coating. On the other hand, the decrease in PCE for $\phi=0.35$ is due to a decrease in the AR effect with an increase in $\phi$ as discussed earlier.

To investigate the substantial PCE enhancement by the $\mathrm{TiO}_{2}$ NW coatings in detail, we performed EQE measurements of the BHJ organic solar cells. In Figure 5(a), the NW coating slightly changed the spectrum. Figure $5(\mathrm{~b})$ shows
TABle 1: Photovoltaic parameters obtained from $J$ - $V$ characteristics under solar simulator (AM $1.5 \mathrm{G}$ ), with the coatings of various surface fractions.

\begin{tabular}{lccccc}
\hline Coverage $\phi$ & $V_{\text {oc }} / \mathrm{V}$ & $J_{\text {sc }} / \mathrm{mAcm}^{-2}$ & $\mathrm{FF}$ & $\mathrm{PCE} / \%$ & $\sigma(\mathrm{PCE})$ \\
\hline $0.00^{*}$ & 0.526 & 7.89 & 0.641 & 2.67 & 0.010 \\
0.11 & 0.527 & 8.00 & 0.636 & 2.68 & 0.011 \\
0.21 & 0.527 & 8.00 & 0.641 & 2.70 & 0.008 \\
0.35 & 0.526 & 7.98 & 0.640 & 2.68 & 0.009 \\
\hline
\end{tabular}

${ }^{*} \mathrm{BHJ}$ organic solar cell without the NW coating.

the change in the EQEs in the presence and absence of the NW coating. The peaks found at $390 \mathrm{~nm}$ and $600 \mathrm{~nm}$ indicate that the photovoltaic effect is improved at certain wavelengths. To confirm the light absorption enhancement, the reflection absorption spectra were measured for the $\mathrm{Al}$ electrode/P3HT : PCBM spin-coated film on quartz with and without the NW coating (a model of the active layer of 
the BHJ solar cell) (Figure 6(a)). The change in reflection absorption is shown in Figure 6(b). This figure shows that light absorption is enhanced around at $390 \mathrm{~nm}, 600 \mathrm{~nm}$, and over $650 \mathrm{~nm}$. The peaks in the wavelength region of $\lambda \leq 600 \mathrm{~nm}$ agreed well with the changes in the EQE (Figure 5(b)) These results support the belief that the coatings enhanced light absorption in the active layer. In addition, the peak around $390 \mathrm{~nm}$ clearly shows that the improvement of the photovoltaic characteristics of the $\mathrm{BHJ}$ organic solar cell is influenced not only by the AR effect but also by light scattering of the $\mathrm{TiO}_{2} \mathrm{NW}$ coating. Because the AR effect is observed only in the wavelength region of $\lambda>560 \mathrm{~nm}$ (see Figure 3), the improvement in EQE around $390 \mathrm{~nm}$ is due to the haze transmission of incident light and light trapping into the active layer due to the light scattering characteristics of $\mathrm{TiO}_{2} \mathrm{NWs}$ [9]. A small decrease in the 420$520 \mathrm{~nm}$ range is due to the reflection of the coatings as also observed in Figure 3. Unfortunately, the large AR effect in the wavelength region of $\lambda>650 \mathrm{~nm}$ is not substantial for the P3HT: PCBM BHJ organic solar cell. This coating would be more substantial for photovoltaics of $\mathrm{BHJ}$ organic solar cells using low-band gap polymers [22].

Another advantage of the $\mathrm{TiO}_{2} \mathrm{NW}$ coating is the anti-glare (AG) effect observed in the dependence of light collection characteristics on the angle of incidence $(\theta)$. As shown in Figure 7, the PCE of the cells with and without the NW coating decreased with an increase in $\theta$ at $\theta \geq 70^{\circ}$. This agreed well with the theoretical predication for incident angle dependency of the number of photons absorbed in the active layer, reported by Dennler et al., and this is also due to the Fresnel reflection at air/glass interface that results in a decrease in the light power density trapped into the active layer [23]. The maximum values of both PCEs around $\theta=60^{\circ}$ may arise from perfect transmission of the TM mode at the Brewster angle of the air/glass interface [23]. For the incident-angle dependence, the PCE of the cell with the NW coating of $\phi=0.21$ was improved compared with that without the NW coating at $\theta \geq 70^{\circ}$. The maximum improvement rate in PCE is $51.6 \%$ at $\theta=85^{\circ}$. Thus, we concluded that the substantial PCE enhancement by the $\mathrm{TiO}_{2}$ NW coatings is due to improvement in the light absorption in the active layer based on AR and the light trapping mechanisms.

\section{Conclusions}

We have prepared $\mathrm{TiO}_{2} \mathrm{NW}$ coatings with various coverage fractions by a simple solution casting on a glass substrate of the $\mathrm{BHJ}$ organic solar cell. The $\mathrm{BHJ}$ organic solar cells with the NW coating showed the improved PCEs due to their $\mathrm{AR}$ and light trapping effects in the active layer. In addition, the incident-angle dependence of PCE was also improved by the AG effect of the NW coating. This versatile and scalable light management approach is compatible with solutionprocessed organic devices, including OPV solar cells. At present, we have not accomplished the optimization of light management of the BHJ organic solar cells through our solution-processed NW coating approach. We conclude that the performance of BHJ organic solar cells will be improved by optimization of some parameters (e.g., refractive index and transparency of the NWs, size distribution control of the NWs, and dispersion control of the NWs). Further studies are now in progress and the results will be reported.

\section{Acknowledgments}

The authors thank Mr. Yuichi Suzuki, Center for Advanced Materials Analysis, Tokyo Institute of Technology, for assistance with the XRD measurements. This work was supported by the "Green Sensor Network System Technology Development Project" from the New Energy and Industrial Technology Department Organization (NEDO).

\section{References}

[1] B. Kippelen and J. L. Brédas, "Organic photovoltaics," Energy and Environmental Science, vol. 2, no. 3, pp. 251-261, 2009.

[2] F. C. Krebs, "Fabrication and processing of polymer solar cells: a review of printing and coating techniques," Solar Energy Materials and Solar Cells, vol. 93, no. 4, pp. 394-412, 2009.

[3] P.-L. T. Boudreault, A. Najari, and M. Leclerc, "Processable low-bandgap polymers for photovoltaic applications," Chemistry of Materials, vol. 23, no. 3, pp. 456-469, 2011.

[4] C. J. Brabec, S. Gowrisanker, J. J. M. Halls, D. Laird, S. Jia, and S. P. Williams, "Polymer-fullerene bulk-heterojunction solar cells," Advanced Materials, vol. 22, no. 34, pp. 3839-3856, 2010.

[5] S. H. Park, A. Roy, S. Beaupré et al., "Bulk heterojunction solar cells with internal quantum efficiency approaching 100\%," Nature Photonics, vol. 3, no. 5, pp. 297-302, 2009.

[6] Y. Liang, Z. Xu, J. Xia et al., "For the bright future-bulk heterojunction polymer solar cells with power conversion efficiency of 7.4\%," Advanced Materials, vol. 22, no. 20, pp. E135-E138, 2010.

[7] D.-H. Ko, J. R. Tumbleston, A. Gadisa et al., "Light-trapping nano-structures in organic photovoltaic cells," Journal of Materials Chemistry, vol. 21, no. 41, pp. 16293-16303, 2011.

[8] K. S. Nalwa and S. Chaudhary, "Design of light-trapping microscale-textured surfaces for efficient organic solar cells," Optics Express, vol. 18, no. 5, pp. 5168-5178, 2010.

[9] E. T. Yu and J. van de Lagemaat, "Photon management for photovoltaics," MRS Bulletin, vol. 36, no. 6, pp. 424-428, 2011.

[10] D. Chen, "Anti-reflection (AR) coatings made by sol-gel processes: a review," Solar Energy Materials and Solar Cells, vol. 68, no. 3-4, pp. 313-336, 2001.

[11] C. M. Lieber, "Semiconductor nanowires: a platform for nanoscience and nanotechnology," MRS Bulletin, vol. 36, no. 12, pp. 1052-1063, 2011.

[12] J. Doshi and D. H. Reneker, "Electrospinning process and applications of electrospun fibers," Journal of Electrostatics, vol. 35, no. 2-3, pp. 151-160, 1995.

[13] D. Li and Y. Xia, "Electrospinning of nanofibers: reinventing the wheel?" Advanced Materials, vol. 16, no. 14, pp. 1151-1170, 2004.

[14] A. Greiner and J. H. Wendorff, "Electrospinning: a fascinating method for the preparation of ultrathin fibers," Angewandte Chemie, vol. 46, no. 30, pp. 5670-5703, 2007.

[15] H. Kuwayama, H. Matsumoto, K. Morota, M. Minagawa, and A. Tanioka, "Control over color of nanotextured coatings by 
electrospray deposition," Sen'i Gakkaishi, vol. 64, no. 1, pp. 14, 2008.

[16] K. Tsuboi, H. Matsumoto, M. Minagawa, and A. Tanioka, "Light scattering assisted surface plasmon resonance at electrospun nanofiber-coated gold surfaces," Applied Physics Letters, vol. 98, no. 24, Article ID 241109, 3 pages, 2011.

[17] S. Chuangchote, T. Sagawa, and S. Yoshikawa, "Efficient dyesensitized solar cells using electrospun $\mathrm{TiO}_{2}$ nanofibers as a light harvesting layer," Applied Physics Letters, vol. 93, no. 3, Article ID 033310, 3 pages, 2008.

[18] Q. Tai, X. Zhao, and F. Yan, "Hybrid solar cells based on poly(3-hexylthiophene) and electrospun $\mathrm{TiO}_{2}$ nanofibers with effective interface modification," Journal of Materials Chemistry, vol. 20, no. 35, pp. 7366-7371, 2010.

[19] A. N. Banerjee, "The design, fabrication, and photocatalytic utility of nanostructured semiconductors: focus on $\mathrm{TiO}_{2}$ based nanostructures," Nanotechnology, Science and Applications, vol. 4, no. 1, pp. 35-65, 2011.

[20] S. Imaizumi, H. Matsumoto, Y. Konosu et al., "Top-down process based on electrospinning, twisting, and heating for producing one-dimensional carbon nanotube assembly," ACS Applied Materials \& Interfaces, vol. 3, no. 2, pp. 469-475, 2011.

[21] T. Tromholt, E. A. Katz, B. Hirsch, A. Vossier, and F. C. Krebs, "Effects of concentrated sunlight on organic photovoltaics," Applied Physics Letters, vol. 96, no. 7, Article ID 073501, 3 pages, 2010.

[22] J. Peet, J. Y. Kim, N. E. Coates et al., "Efficiency enhancement in low-bandgap polymer solar cells by processing with alkane dithiols," Nature Materials, vol. 6, no. 7, pp. 497-500, 2007.

[23] G. Dennler, K. Forberich, M. C. Scharber et al., "Angle dependence of external and internal quantum efficiencies in bulk-heterojunction organic solar cells," Journal of Applied Physics, vol. 102, no. 5, Article ID 054516, 7 pages, 2007. 

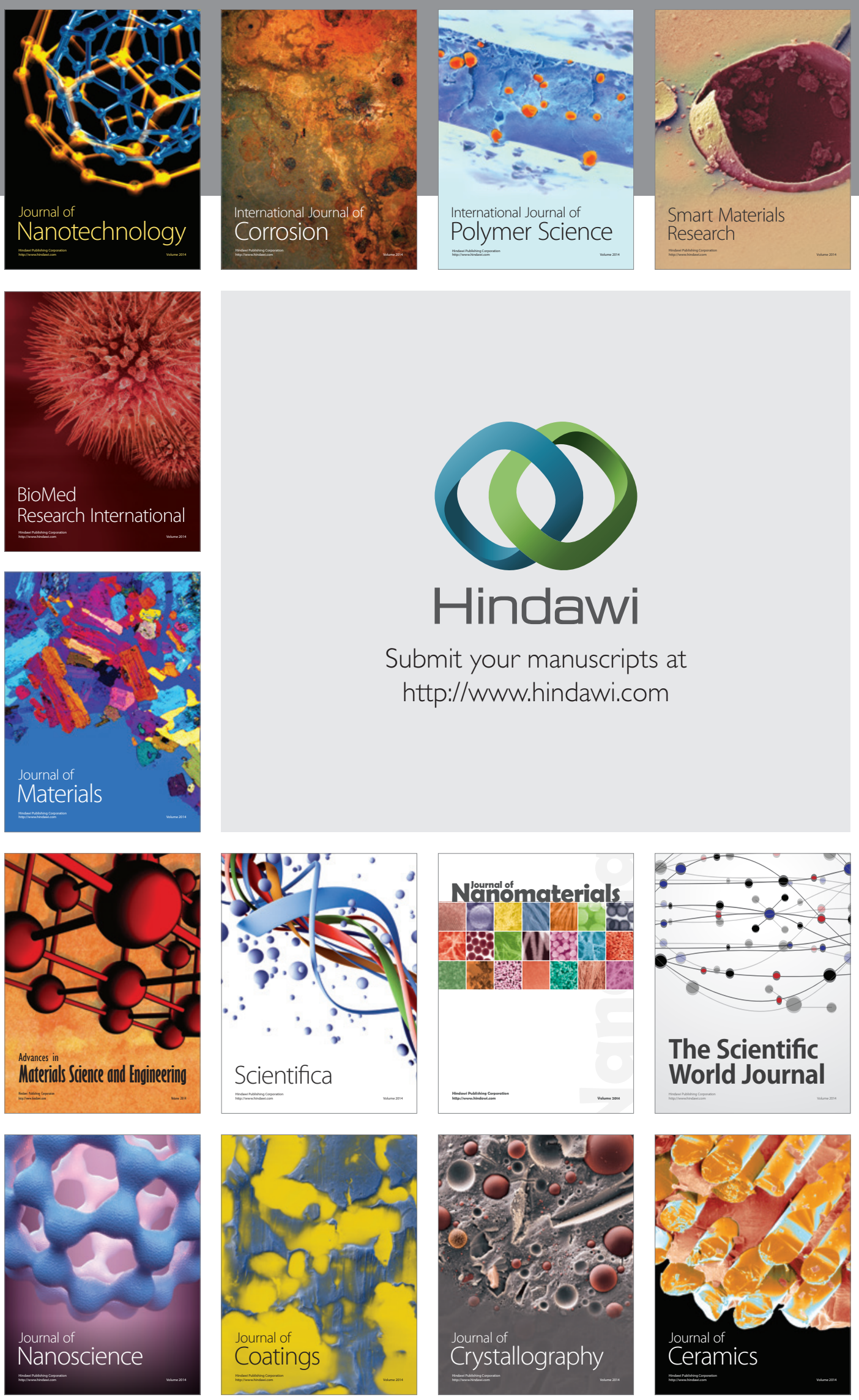

The Scientific World Journal

Submit your manuscripts at

http://www.hindawi.com

\section{World Journal}

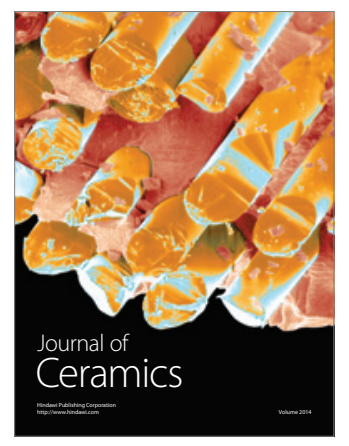

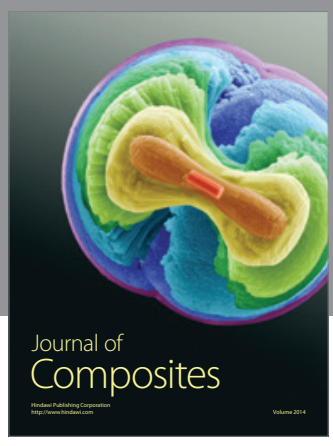
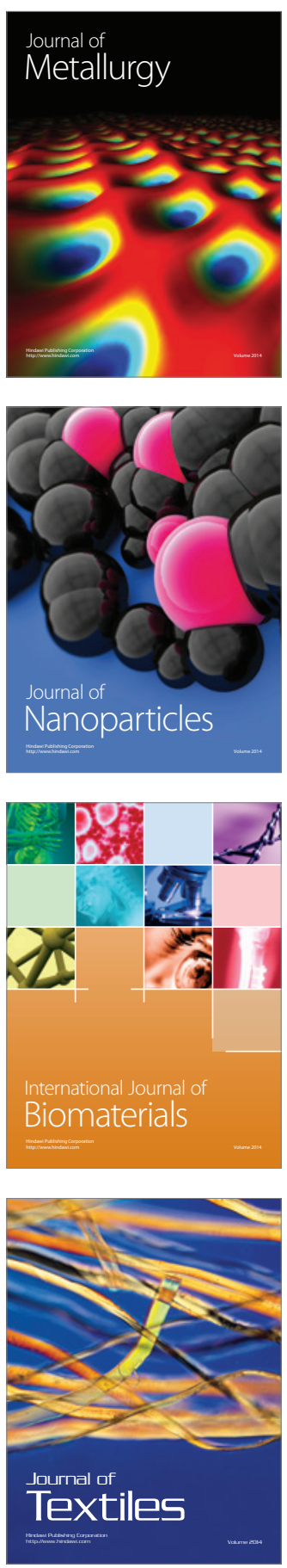